\title{
COMPARISON OF PROPHYLACTIC ANTIEMETIC EFFICACY OF HALOPERIDOL AND GRANISETRON FOR THE PREVENTION OF POSTOPERATIVE NAUSEA AND VOMITING FOLLOWED BY LAPAROSCOPIC SURGERIES
}

Sunil B. V1, Sonal Bhat ${ }^{2}$, Narendra ${ }^{3}$

${ }^{1}$ Associate Professor, Department of Anaesthesia, KMC, Mangalore.

${ }^{2}$ Associate Professor, Department of Anaesthesia, KMC, Mangalore.

3Junior Resident, Department of Anaesthesia, KMC, Mangalore.

\begin{abstract}
\section{BACKGROUND}

Postoperative Nausea and Vomiting (PONV) continues to be a highly undesirable outcome of anaesthesia and surgery. For example, in the ambulatory care surgery setting PONV is among the most common complications with a frequency ranging from $30 \%$ to $50 \% .{ }^{1}$ In addition, significant or uncontrolled PONV in the ambulatory surgery Post Anaesthesia Care Unit (PACU) can lead to unanticipated hospital admission. Although routine antiemetic prophylaxis is clearly unjustified, patients at high risk for postoperative emesis should receive special considerations with respect to the prophylactic use of antiemetic drugs. ${ }^{2}$ Retching or vomiting following surgery can put tension on suture lines, cause haematomas beneath surgical flaps and place the patient at risk for pulmonary aspiration of vomit if airway reflexes are depressed from the lingering effects of anaesthetic and analgesic drug.
\end{abstract}

\section{AIM}

To compare the prophylactic antiemetic efficacy of Haloperidol versus Granisetron groups for the prevention of postoperative nausea and vomiting in patients posted for laparoscopic surgeries.

\section{MATERIALS AND METHODS}

After obtaining Ethics Committee approval, adult patients with age from 18 to 65 yrs. with ASA grade 1 and 2 posted for laparoscopic surgeries were selected. Patients were divided into 2 groups of 30 patients each as Haloperidol group and Granisetron group. Balanced Anaesthesia was maintained with $\mathrm{N}_{2} \mathrm{O}+\mathrm{O}_{2}+$ Isoflurane+fentanyl and vecuronium $1 \mathrm{mg}$ based on neuromuscular monitoring; 30 minutes prior to end of surgery group $\mathrm{H}$ patients received Haloperidol - $2 \mathrm{mg}$ IV, group G patients received Granisetron - $1 \mathrm{mg}$ IV. Results were statistically analysed using Student's unpaired t-test, Chi-square test and ANOVA analysis. P value less than 0.05 was considered statistically significant.

\section{RESULT}

Comparison of incidence of nausea and vomiting in the 2-24 hrs. postoperative period shows no statistically significant difference between 2 groups.

\section{CONCLUSION}

Prophylactic administration of antiemetics does reduce incidence and suffering due to PONV and its consequences. Prophylactic IV administration of Haloperidol $2 \mathrm{mg}$ is as effective as Granisetron in reducing the incidence of PONV in laparoscopic surgeries. Granisetron causes headache as adverse effect, Haloperidol does not have serious adverse effect at doses used for PONV.

\section{KEYWORDS}

Granisetron, Haloperidol, Postoperative Nausea and Vomiting.

HOW TO CITE THIS ARTICLE: Sunil BV, Bhat S, Narendra. Comparison of prophylactic antiemetic efficacy of haloperidol and granisetron for the prevention of postoperative nausea and vomiting followed by laparoscopic surgeries. J. Evolution Med. Dent. Sci. 2016;5(78):5778-5782, DOI: 10.14260/jemds/2016/1304

\section{INTRODUCTION}

Nausea is defined as a subjective unpleasant sensation in which the patient is aware of the urge to vomit, but does not necessarily do so.

\section{Financial or Other, Competing Interest: None}

Submission 16-07-2016, Peer Review 17-09-2016,

Acceptance 22-09-2016, Published 27-09-2016.

Corresponding Author:

Dr. Sunil B. V.

Associate Professor

Department of Anaesthesia

Attavara, KMC, Mangalore.

E-mail:drsunilbv@gmail.com

DOI: $10.14260 /$ jemds $/ 2016 / 1304$

\section{(c) $(1) \ominus$}

Vomiting is defined as an objective physical motion characterised by contraction of the abdominal muscles, descent of the diaphragm, and opening of the gastric cardia resulting in expulsion of stomach contents from the mouth.

Nausea is mediated by neural pathways, whereas vomiting is initiated and coordinated by the vomiting center and the Chemoreceptor Trigger Zone (CTZ). After stimulation of the vomiting center, efferent pathways involving the salivary, respiratory and vasomotor centers and cranial nerves mediate vomiting. ${ }^{3-5}$ Activation of several receptors leads to nausea or vomiting; most antiemetic drugs exert their effects by blocking one or more of these receptors. "Dopamine type $2\left(D_{2}\right)-$ receptors are located in the stomach, the Nuclei Tractus Solitarii (NTS), and the Chemoreceptor Trigger Zone (CTZ).

$\mathrm{D}_{2}$-receptors in the stomach appear to mediate the inhibition of gastric motility that occurs during nausea and 
vomiting, and they participate in reflexes that relax the upper portion of the stomach and delay gastric emptying. $\mathrm{D}_{2}-$ receptors are also implicated in emetic signalling at the CTZ and in the NTS. Serotonin, acting at the serotonin type 3 (5$\mathrm{HT}_{3}$ )-receptor is an important neurotransmitter in the afferent pathways from the stomach and small intestine as well as centrally in the CTZ, area postrema and NTS. Histamine type 1 $\left(\mathrm{H}_{1}\right)$-receptors and muscarinic cholinergic type $1\left(\mathrm{M}_{1}\right)$ receptors are concentrated in the NTS, CTZ and vestibular system.

\section{Other Considerations in the Prevention of PONV Anaesthetic Factors}

Soon after propofol was approved for marketing as an IV anaesthetic agent, a number of articles were published indicating that propofol was associated with a significant decrease in PONV.6,7 In animal models, propofol has been shown to decrease synaptic nerve transmission in the olfactory cortex and to decrease serotonin levels in the area postrema. ${ }^{8}$ A systematic review of PONV following maintenance anaesthesia with propofol or an inhalational anaesthetic agent found that patients receiving propofol had a significantly lower frequency of PONV regardless of induction agent, choice of inhalational agent, use of nitrous oxide, patient age or use of an opioid. ${ }^{9}$ Another systematic review found that propofol may be effective in reducing PONV in the short term, but only when given as a continuous infusion for maintenance of anaesthesia and when the PONV event rate is greater than $20 \%$ (e.g. in moderate to high-risk patients). ${ }^{10}$ There is evidence of a relationship between plasma propofol concentration and antiemetic efficacy. Gan et al found that a median plasma propofol concentration of $343 \mathrm{ng} / \mathrm{mL}$ was associated with a reduction in Postoperative Vomiting (PV) in surgical patients. ${ }^{11}$ Therefore, the common practice of selecting propofol for inducing anaesthesia, because of its antiemetic effects in day care procedures.

\section{Nitrous Oxide}

Nitrous oxide is known to cause nausea and vomiting when it is administered as the sole anaesthetic agent. ${ }^{12}$ Nitrous oxide also causes PONV due to changes in middle ear pressure ${ }^{13}$ or bowel distention due to diffusion into closed cavities. ${ }^{14}$ In an animal model, nitrous oxide activated the medullary dopaminergic system. ${ }^{15}$ Three systematic reviews concluded that omitting nitrous oxide from a general anaesthetic in highrisk patient (e.g. those undergoing gynaecological procedures) decreases the risk of PONV. ${ }^{16-18}$

\section{Hydration Status}

Postoperative outcomes such as thirst, dizziness, drowsiness and nausea may be influenced by the surgical patient's fluid status before and after surgery. Pre-operative dehydration may occur due to the preoperative nothing-by-mouth (NPO) orders that often go into effect many hours before surgery. Preoperative dehydration may be compounded in a patient whose scheduled surgery is delayed. Aggressive perioperative hydration with infusions at rates of up to $20 \mathrm{~mL} / \mathrm{kg} / \mathrm{hr}$. has been shown to effectively deter Postoperative Nausea (PN) as well as thirst, dizziness and drowsiness. ${ }^{19}$

Recently, more liberal preoperative NPO guidelines have been introduced in an effort to avoid preoperative dehydration. ${ }^{20}$

\section{Reversal Agents}

Anticholinesterase drugs are routinely administered at the end of surgery to antagonise any residual effect of nondepolarising neuromuscular blocking agents. These agents may contribute to PONV, because they increase gastrointestinal motility and gastric secretions. In actual practice, these effects are usually countered by concurrent administration of an anticholinergic agent, such as glycopyrrolate. A systematic review of the effect of omitting reversal agents on the risk for PONV found little evidence of benefit unless large doses $(>2.5 \mathrm{mg}$ of neostigmine methylsulfate) were used. ${ }^{21}$

\section{Oxygen}

It has been hypothesised that the high frequency of PONV seen with abdominal procedures may be related to surgical compression and manipulation causing tissue ischaemia and the release of serotonin from gastrointestinal tissues. ${ }^{22,23}$ High inspired-oxygen concentrations may counter the tissue hypoxia resulting from surgical manipulation, thereby preventing serotonin release.

\section{Gastric Suctioning}

Gastric suctioning may be useful in reducing PONV following procedures involving the nose, mouth and oropharynx, in which large amounts of blood (a potent emetogenic) can enter the stomach. Gastric distention resulting from vigorous positive-pressure ventilation through a facemask may also cause vomiting. ${ }^{2}$ Gastric distention can be reduced by suctioning before extubation. In general however gastric suctioning has not been shown to reduce PONV; in fact, the presence of a nasogastric tube during the postoperative period may stimulate the gag reflex. ${ }^{24}$

\section{Inhalational (Volatile) Anaesthetic Agents}

The use of inhalational anaesthetic agents was the strongest risk factor in the development of PONV. However, this emetogenic effect was primarily evident in the early postoperative period (up to two hours) and was mostly dependent on the duration of anaesthesia, particularly in procedures lasting longer than three hours. Therefore, omitting inhaled anaesthetics may be more efficacious for avoiding PONV in high-risk patients than administering a prophylactic antiemetic. 25

\section{MATERIAL AND METHODS}

After obtaining Ethics Committee approval, adult patients with age from 18 to 65 yrs. with ASA grade 1 and 2 posted for laparoscopic surgeries were selected. Patients were divided into 2 groups of 30 patients each as Haloperidol group and Granisetron group.

Other exclusion factors are patients with obvious airway problems, obesity with BMI $>25$, pregnant patients, patients with chronic cough/psychiatric illness/significant major organ disease, patient who has consumed an antiemetic medication within $24 \mathrm{hrs}$. prior to commencing study were also excluded from the study. Informed and written consent was taken, anaesthesia was standardised.

All patients were premedicated with Fentanyl $2 \mathrm{mcg} / \mathrm{kg}$ body wt. Patients were connected to monitors like noninvasive blood pressure, pulse oxymeter, ECG. Induction was done with propofol $2 \mathrm{mg} / \mathrm{kg}$ body wt. Intubated after 
neuromuscular blockade with vecuronium $0.1 \mathrm{mg} / \mathrm{kg} / \mathrm{body}$ wt. Anaesthesia was maintained with $\mathrm{N}_{2} \mathrm{O}+\mathrm{O}_{2}+$ Isoflurane +vecuronium $1 \mathrm{mg}$ based on neuromuscular monitoring; 30 minutes prior to end of surgery group $\mathrm{H}$ patients received Haloperidol-2 mg IV and group G patients received Granisetron - $1 \mathrm{mg}$ IV. All patients received Inj. Diclofenac 50 mg IM 30 minutes before the end of the surgery. After the surgery was over, residual neuromuscular blockade was reversed with neostigmine - $0.05 \mathrm{mg} / \mathrm{kg} / \mathrm{body}$ wt. and glycopyrrolate $-0.01 \mathrm{mg} / \mathrm{kg} /$ body wt. Extubation was done when patient was fully awake. For evaluation postoperative period was divided into 3 periods, early postoperative period as $0-2 \mathrm{hrs}$., late postoperative period as $2-24 \mathrm{hrs}$. and third period as $0-24 \mathrm{hrs}$. time period following anaesthesia.

\section{Following Observations were Made}

1. Recovery time (in minutes): From the time of discontinuation of anaesthesia until opening of eyes.

2. Sedation level: After recovery from anaesthesia was assessed by Modified Observer's Assessment of Alertness/Sedation scale (OAA). ${ }^{26}$

\begin{tabular}{|ll|c|}
\hline \multicolumn{1}{|c|}{ Responsiveness } & Score \\
\hline A. & $\begin{array}{l}\text { Response readily to name spoken in a } \\
\text { normal time }\end{array}$ & 5 \\
\hline B. & $\begin{array}{l}\text { Lethargic response to name spoken in a } \\
\text { normal time }\end{array}$ & 4 \\
\hline C. & $\begin{array}{l}\text { Response only after name is called loudly } \\
\text { and Repeatedly }\end{array}$ & 3 \\
\hline D. & Response only after mild prodding /shaking & 2 \\
\hline E. & Does not respond to mild prodding /shaking & 1 \\
\hline F. & Does not respond to test stimulus & 0 \\
\hline
\end{tabular}

3. Pain score was assessed by $10 \mathrm{~cm}$ Visual Analog Scale, where $0 \mathrm{~cm}$ is taken as no pain and $10 \mathrm{~cm}$ as worst pain.

4. Nausea Score: The intensity of each nausea episode was graded as:

- $\quad$ Mild - Discomfort noticed, but no disruption of anticipated normal activity.

- $\quad$ Moderate - Discomfort sufficient enough to affect anticipated normal activity.

- $\quad$ Severe - Inability to perform normal activity.

5. Episodes of Vomiting: A vomiting episode was defined as vomiting events occurring in rapid sequence within a oneminute period. If the interval between two bouts of emesis exceeded one minute, they were considered separate episode.

6. Rescue Antiemetic: Inj. Metoclopramide $10 \mathrm{mg}$ IV was given if patient vomited.

7. ECG - Monitoring was done with lead-II for measurement of $\mathrm{QT}_{\mathrm{c}}$ interval 10 minutes after administration of study drug.

8. Side effects profile of haloperidol and granisetron like headache, constipation, dizziness, extrapyramidal symptoms were observed and noted.

9. Inj. Diclofenac Sodium $50 \mathrm{mg}$ IM was given at the end of surgery.

\section{Statistical Analysis}

Students unpaired t-test, Chi-square test and ANOVA was used for analysis. $P$ value less than 0.05 was considered statistically significant.

\section{RESULTS}

60 patients selected and they were divided into 30 patients in each group. Table 1 shows mean age distribution in haloperidol group of $40 \mathrm{yrs}$., in granisetron group of 41.37 with $P$ value of 0.833 , which is statistically not significant. There has been no significant difference in gender and weight distribution between 2 groups. Duration of surgery in 2 groups shows no significant difference between them with $p$ value of 0.182 .

Recovery time in minutes after ANOVA analysis shows no statistically significant difference between 2 groups. The sedation score is significantly more in haloperidol group compared to granisetron group with a $\mathrm{P}$ value of 0.033 .

Pain score are comparable between the two study groups. There has been no statistically significant difference in the incidence of nausea and vomiting in $0-2 \mathrm{hrs}$. postoperative period between 2 groups. Comparison of incidence of nausea and vomiting in the $2-24 \mathrm{hrs}$. postoperative period shows no statistically significant difference between 2 groups.

We identified increased incidence of adverse effect as headache with granisetron of $20 \%$, which is statistically significant.

\section{DISCUSSION}

PONV is one of the main complaints in patients undergoing laparoscopic surgeries under General Anaesthesia. It is one of the most important factor that determines the length of the hospital stay after ambulatory anaesthesia. ${ }^{27}$ Numerous factors can affect PONV such as age, gender, obesity, motion sickness, history of PONV, duration of surgery, anaesthetic technique, use of opioids and pain. Haloperidol is used effectively in prevention of PONV by many observers at various doses and combinations. T. F. Wang et $\mathrm{al}^{28}$ evaluated the prophylactic effect of low-dose haloperidol (1 mg) on postoperative nausea and vomiting (PONV) in women undergoing ambulatory laparoscopic surgery. Concluded that like droperidol $(0.625 \mathrm{mg}$ ), prophylactic intravenous haloperidol ( $1 \mathrm{mg}$ ) significantly reduced the incidence of PONV in women undergoing ambulatory laparoscopic surgery. Grecu $\mathrm{L}^{29}$ et al studied haloperidol $1 \mathrm{mg}$ and ondansetron $4 \mathrm{mg}$ for postoperative nausea and vomiting prophylaxis. They concluded that the postoperative nausea and vomiting prophylaxis with both drugs was significantly more effective and longer lasting than ondansetron alone. There was no detectable increase in side effects. Rosow et al ${ }^{27}$ studied two hundred and forty four adults who were randomised to receive IV haloperidol $1 \mathrm{mg}$ or ondansetron $4 \mathrm{mg}$ during general anaesthesia. They concluded that in a mixed surgical population, the efficacy and toxicity of postoperative nausea and vomiting prophylaxis with haloperidol $1 \mathrm{mg}$ was not significantly different from ondansetron $4 \mathrm{mg}$.

Our selection of the drug dosages was based on the previous work by Lee $\mathrm{Y}^{30}$ Buttner et $\mathrm{al}^{31}$ for haloperidol and Wilson et $\mathrm{al}^{32}$ for Granisetron. Lee $\mathrm{Y}$ et $\mathrm{al}^{30}$ compared the prophylactic antiemetic efficacy of haloperidol vs. ondansetron for the prevention of Postoperative Nausea and Vomiting (PONV) after general anaesthesia. Approximately 30 mins. before the end of surgery, patients were randomly assigned to receive either haloperidol $2 \mathrm{mg}$ IV or ondansetron $4 \mathrm{mg}$ IV, respectively. Concluded that haloperidol $2 \mathrm{mg}$ IV given 30 mins. before the end of surgery was effective in preventing PONV with efficacy comparable to ondansetron $4 \mathrm{mg}$ IV for the 
first $24 \mathrm{hrs}$. after general anaesthesia. Buttner et al ${ }^{31}$ observed that haloperidol $2 \mathrm{mg}$ is better than $1 \mathrm{mg}$ in preventing PONV. Wilson $\mathrm{J} A$ et $\mathrm{al}^{30}$ studied the single dose IV granisetron in the prevention of PONV in adult patients undergoing elective open abdominal surgery or vaginal hysterectomy during general anaesthesia.

The two higher doses of granisetron (1.0 mg and $3.0 \mathrm{mg}$ ) provided effective prophylaxis against vomiting with $78 \%$ and $77 \%$ of patients respectively, being free from vomiting in the first $6 \mathrm{hrs}$. after surgery, and $63 \%$ and $62 \%$ in the first $24 \mathrm{hrs}$. He concluded that $1 \mathrm{mg}$ granisetron is the optimum dose. Mikawa et $\mathrm{al}^{33}$ conducted study defining the optimal dose of granisetron for prophylaxis against PONV after gynaecological surgery and they found that granisetron markedly decreases PONV at doses of $5 \mathrm{mcg} / \mathrm{kg}$ or larger. In our study drug was given 30 minutes before the end of surgery as peak plasma concentration from IV injection is $>15$ mins. Vella-Brincat et al $2004 .{ }^{34}$ In contrast Yang YL et al suggested that the timing of administration of haloperidol $2 \mathrm{mg}$ IV did not influence its antiemetic efficacy. ${ }^{35}$

The recovery profiles were also similar whether haloperidol was administered at the start or at the end of surgery. In our study, incidence of nausea in Haloperidol group was 4 cases $(13.3 \%)$, all of mild intensity. In granisetron group nausea episodes were seen in 7 cases (23.3\%), of which 5 cases mild and 2 cases had moderate nausea. Incidence of vomiting in Haloperidol group was 5 cases (16.7\%), of which one case had 2 episodes of vomiting. In contrast, Lee $\mathrm{Y}$ et al ${ }^{30}$ had an incidence of PONV of $28 \%$ with haloperidol where study was done on different kind of surgeries. In granisetron group, 3 cases $(10 \%)$ had vomiting of which one case had 2 episodes. So there was no statistical significant difference in incidence of vomiting between Haloperidol group and Granisetron group. In control group 13 cases (43.33\%) had vomiting, of which 3 patients had 2 episodes of vomiting. Incidence is $43.33 \%$ in early postoperative period compared to $10 \%$ in late postoperative period. Apfel C C et al ${ }^{25}$ suggested volatile anaesthetics were the leading cause of early postoperative vomiting.

In patients at high risk for PONV, it would therefore make better sense to avoid inhalational anaesthesia rather than simply to add an antiemetic, which may still be needed to prevent or treat delayed vomiting. Paul F. White et $\mathrm{al}^{36}$ designed prospective observational study to assess the relationship between common patient risk factors for developing PONV and the occurrence of early (0-24 hrs.) versus late (24-72 hrs.) emetic symptoms. It was concluded that despite the frequent use of multiple antiemetic drugs for prophylaxis, an Apfel risk score of three or four (vs 2) was associated with a higher incidence of emetic sequelae in the first $24 \mathrm{hrs}$. after surgery.

However, the occurrence of late (24-72 hrs.) emetic symptoms was low and appeared to be unrelated to the patient's Apfel risk score. Regarding the role of neostigmine, Ching-Rong Cheng et $\mathrm{al}^{37}$ re-evaluated the effect of neostigmine on postoperative nausea and vomiting, while considering the different anticholinergics as potentially confounding factors.

They found the combination of neostigmine with either atropine or glycopyrrolate did not significantly increase the incidence of overall ( $0-24 \mathrm{hrs}$.) vomiting (relative risk, 0.91; $95 \%$ confidence interval, $0.70-1.18 ; \mathrm{P}=0.48$ ) or nausea (relative risk, 1.24; 95\% confidence interval, 0.98-1.59; $\mathrm{P}=$ 0.08). In our study in all patients who had episode of vomiting, duration of surgery was long compared to patients who did not vomit.

Regarding surgical duration, Tseng $L$ et al ${ }^{38}$ estimated the incidence of Postoperative Nausea and Vomiting (PONV) in women undergoing major gynaecologic laparoscopic surgery with an expected surgical duration exceeding 1 hour and anticipated overnight hospitalisation. It was concluded that a long surgical period may have great impact on the PONV in women who undergo gynaecologic laparoscopic surgery, which implies the need for skilled gynaecologic laparoscopists. During our study, all the patients who had vomiting were given $10 \mathrm{mg}$ of Inj. Metoclopramide intravenously as rescue antiemetic. Buttner et $\mathrm{al}^{31}$ observed sedation and extrapyramidal side effects at higher doses $>4 \mathrm{mg}$. In our study, sedation was significantly more in haloperidol group $(\mathrm{P}=$ 0.033) when compared to granisetron.

But sedation score was comparable between haloperidol and control group. But recovery time from anaesthesia was not significantly different from granisetron. In our study, none of the patients had QTc interval prolongation. Considering side effect profile of granisetron in our study, 6 cases (20\%) in granisetron group had headache which is statistically significant. Limitations of our study: Patients with history of motion sickness are known to have a higher incidence of PONV. This study does not evaluate such patients and their response to being treated with haloperidol or granisetron. Patients with previous history of PONV were also not evaluated separately. This study has not assessed cost-effectiveness of PONV prophylaxis.

\section{CONCLUSION}

Prophylactic administration of antiemetics does reduce incidence and suffering due to PONV and its consequences. Prophylactic IV administration of Haloperidol $2 \mathrm{mg}$ is as effective as granisetron in reducing the incidence of PONV in laparoscopic surgeries, Granisetron causes headache as adverse effect, Haloperidol does not have serious adverse effect at doses used for PONV.

\section{REFERENCES}

1. Gan TJ. Postoperative nausea and vomiting: can it be eliminated? JAMA 2002;287(10):1233-6.

2. Watcha MF, White PF. Postoperative nausea and vomiting. Its etiology, treatment, and prevention. Anesthesilogy 1992;77(1):162-84.

3. Kovac AL. Prevention and treatment of postoperative nausea and vomiting. Drugs 2000;59(2):213-43.

4. Ockner RK. Cecil text book of medicine. 20 $0^{\text {th }}$ edn Philadelphia: Saunders 1996:627-30.

5. American society of health system pharmacists. ASHP guidelines for management of PONV. Am J Health-System Pharmacists 1999;56:729-64.

6. Smith I, White PF, Nathanson M, et al. Propofol. An update on its clinical use. Anesthesiology 1994;81(4):1005-43.

7. Borgeat A, Wilder-Smith $\mathrm{OH}$, Suter PM. The nonhypnotic therapeutic applications of propofol. Anesthesiology 1994;80:642-56.

8. Diab A, Gelb AW, Cechetto DF. Effect of the anesthetic propofol on 5-ht and fos in the rat brain. Neuroscience 1994;20:1169. 
9. Sneyd JR, Carr A, Byrom WD, et al. A meta-analysis of nausea and vomiting following maintenance of anesthesia with propofol or inhalation agents. Eur J Anaesth 1998;15(4):433-45.

10. Tramer M, Moore A, McQuay H. Propofol anesthesia and PONV. Br J Anaesth 1997;78(3):247-55.

11. Gan TJ, Glass PS, Howell ST, et al. Determination of plasma concentrations of propofol associated with $50 \%$ reduction in postoperative nausea. Anesthesiology 1997; 87(4):779-84.

12. Hornberg TF, Eger El, Winter PM, et al. The minimum alveolar concentration of nitrous oxide in man. Anaesth Analg 1982;61(7):553-6.

13. Perreault L, Normandin N, Plamondon L, et al. Middle ear pressure variations during nitrous oxide and oxygen anesthesia. Can Anaesth Soc J 1982;29(5):428-34.

14. Eger l, Saidman LJ. Hazards of nitrous oxide in bowel obstruction and pnemothorax. Anaesthesilogy 1965;26:61-6.

15. Murakawa M, Adachi T, Nakao S, et al. Activation of cortical and medullary dopaminergic systems by nitrous oxide in rats. Anesth Analg 1994;78(2):376-81.

16. Tramer M, Moore A, McQuay H. Meta-analytic comparision of prophylactic anti-emetic efficacy for PONV: propofol vs omitting nitrous oxide vs total IV anesthesia with propofol. Br J Anaesth 1997;78(3):256-9.

17. Hartung J. Twenty four of twenty seven studies show greater incidence of emesis associated with nitrous oxide than with alternative anesthetics. Anaesth Analg 1996; 83(1):114-6.

18. Tramer M, Moore A, McQuay H. Omitting nitrous oxide in general anesthesia: meta-analysis of intraoperative awareness and postoperative emesis in randomized control studies. Br J Anaesth 1996;76(2):186-93.

19. Yogendran S, Asolkumar B, Cheng DC, et al. A prospective randomized double blind study of the effect of intravenous fluid therapy on adverse outcomes on outpatient surgery. Anesth Analg 1995;80(4):682-6.

20. Ljungquist O, Soriede E. Preoperative fasting. Br J Surg 2003;90(4):400-6.

21. Tramer $M$, Fuchs-Buder T. Omitting antagonism of neuromuscular block: effect on PONV. Br J Anesth 1999;82(3):379-86.

22. Granger DN, Richardson PD, Kvietys PR, et al. Intestinal bloodflow. Gastroenterology 1980;78(4):837-63.

23. Martson A. Responses of the splanchnic circulation to ischaemia. J Clin Pathol Suppl (R Coll Pathol) 1977;11: 59-67.
24. Hovorka J, Kotilla K, Erkola O. Gastric aspiration at the end of anaesthesia does not decrease PONV. Anesth Intensive Care 1990;18(1):56-61.

25. Apfel CC, Kranke P, Kartz MH, et al. Volatile anesthetics may be the cause of early but not delayed postoperative vomiting: a randomized controlled trial of factorial design. Br J Anesth 2002;88(5):659-68.

26. Bauerle K, Greim CA, Schroth M, et al. Prediction of depth of sedation and anaesthesia by the narcotrend EEG monitor. BJA 2004;92(6):841-5.

27. Rosow CE, Haspel KL, Smith SE, et al. Haloperidol vs ondansetron for prophylaxis of PONV. Anesth Analg 2008;106(5):1407-9.

28. Wang TF, Liu YH, Chu CC, et al. Low dose haloperidol prevents PONV after ambulatory laparoscopic surgery. Acta Anaesthesiologica Scandinavica 2008;52(2):280-4.

29. Grecu L, Bittner EA, Kher J, et al. Haloperidol plus ondansetron versus ondansetron alone for prophylaxis of postoperative nausea and vomiting. Anesth Analg 2008;106(5):1410-3.

30. Lee Y, Wang PK, Lai HY, et al. Haloperidol is as effective as ondansetron for PONV. Can J Anesth 2007;54(5):349-54.

31. Büttner $M$, Walder $B$, von Elm $E$, et al. Is low-dose haloperidol a useful antiemetic? A meta-analysis of published and unpublished randomized trials. Anaesthesiology 2004;101(6):1454-63.

32. Wilson AJ, Diemunsch P, Lindeque BG, et al. Single-dose i.v. granisetron in the prevention of PONV. Br J Anaesth 1996;76(4):515-8.

33. Mikawa K, Takao Y, Nishina K, et al. Optimal dose of granisetron for prophylaxis against postoperative emesis after gynecological surgery. Anesth Analg 1997; 85(3): 652-6.

34. Vella-Brineat J, Macleod AD . Haloperidol in palliative care. Palliate Med 2004;18(3):195-201.

35. Yang YL, Lai HY, Wang JJ, et al. The timing of haloperidol administration does not affect its prophylactic antiemetic efficacy. Can J Anaesth 2008;55(5):270-5.

36. White PF, Sacan O, Nuangchamnong N, et al. The relation between patient risk factors and early versus late postoperative emetic symptoms. Anesth Analg 2008;107(2):459-63.

37. Cheng CR, Sessler DI, Apfel CC. Does neostigmine produce a clinically important increase in PONV. Anesth Analg 2005;101(5):1349-55.

38. Tseng LH, Liou SC, Chang TC, et al. A randomized blinded study of the incidence of PONV in women after major gynecologic laparoscopic surgeries. Journal of Minimally Invasive Gynecology 2006;13(5):413-7. 